\title{
A novel mycothiol-dependent thiol-disulfide reductase in Corynebacterium glutamicum involving oxidative stress resistance
}

\author{
Yang $\mathrm{Liu}^{1} \cdot \mathrm{Xiaona}_{\mathrm{Li}}{ }^{1} \cdot \operatorname{Jiaxin} \mathrm{Luo}^{1} \cdot \mathrm{Tao}^{\mathrm{Su}}{ }^{1} \cdot \mathrm{Meiru} \mathrm{Si}^{1}{ }^{10} \cdot \mathrm{Can}_{\mathrm{Chen}}{ }^{2}$
}

Received: 19 January 2021 / Accepted: 12 June 2021 / Published online: 14 July 2021

(c) The Author(s) 2021

\begin{abstract}
ncgl2478 gene from Corynebacterium glutamicum encodes a thiol-disulfide oxidoreductase enzyme annotated as dithioldisulfide isomerase DsbA. It preserves a Cys-Pro-Phe-Cys active-site motif, which is presumed to be an exclusive characteristic of the novel DsbA-mycoredoxin 1 (Mrx1) cluster. However, the real mode of action, the nature of the electron donor pathway and biological functions of $\mathrm{NCg} 12478$ in C. glutamicum have remained enigmatic so far. Herein, we report that NCgl2478 plays an important role in stress resistance. Deletion of the $n c g l 2478$ gene increases the size of growth inhibition zones. The $n c g l 2478$ expression is induced in the stress-responsive extra-cytoplasmic function-sigma (ECF- $\sigma$ ) factor $\mathrm{SigH}-d e p e n d e n t$ manner by stress. It receives electrons preferentially from the mycothiol (MSH)/mycothione reductase (Mtr)/NADPH pathway. Further, NCgl2478 reduces $S$-mycothiolated mixed disulfides and intramolecular disulfides via a monothiol-disulfide and a dithiol-disulfide exchange mechanism, respectively. NCg12478 lacks oxidase activity; kinetic properties of its demycothiolation are different from those of Mrx1. Site-directed mutagenesis confirms Cys24 is the resolving Cys residue, while Cys21 is the nucleophilic cysteine that is oxidized to a sulfenic acid and then forms an intramolecular disulfide bond with Cys 24 or a mixed disulfide with MSH under oxidative stress. In conclusion, our study presents the first evidence that $\mathrm{NCgl} 2478$ protects against various stresses by acting as an MSH-dependent thiol-disulfide reductase, belonging to a novel DsbA-Mrx1 cluster.
\end{abstract}

Keywords Thiol-disulfide interchange protein $(\mathrm{DsbA}) \cdot$ Corynebacterium glutamicum $\cdot$ Oxidative stress $\cdot$ SigH

\section{Introduction}

Corynebacterium glutamicum, a well-known various L-amino acid producer in industrial applications and a model organism in systems biology, unavoidably generates or encounters a series of unfavorable circumstances in the fermenting process (Bröer et al. 1993). Various environmental insults, including oxidants, heavy metals, antibiotics, alkylating agents, and acids, induce accumulation of excessive reactive

Yang Liu and Xiaona Li contributed equally to this work.

Can Chen designed the research. Can Chen and Meiru Si supervised the research. Can Chen and Meiru Si revised the paper.

Meiru Si

Simeiru100@126.com

1 College of Life Sciences, Qufu Normal University, Qufu 273165, Shandong, China

2 College of Life Science and Agronomy, Zhoukou Normal University, Zhoukou 466001, Henan, China oxygen species (ROS) (Halliwell and Gutteridge 1984). These excessive ROS are highly reactive molecules that are not only capable of damaging cellular constituents such as DNA, RNA, lipids, and proteins, but also destroying intracellular redox homeostasis and provoking oxidative stress (Jiang et al. 2019; Storz et al. 1987). Thus, to survive within the diverse fermentation environment, $C$. glutamicum acquires a variety of mechanisms to protect its cellular constituents from ROS and maintain its redox equilibrium (Dalle-Donne et al. 2008). One of these mechanisms is the use of a low molecular weight (LMW) defense mechanism. In C. glutamicum, millimolar concentrations of MSH (mycothiol; chemically 1D-myo-inosityl-2-[ $N$ acetyl-L-cysteinyl] amido-2-deoxy- $\alpha$-D-glucopyranoside), a pseudodisaccharide containing a cysteine moiety as a reactive thiol, is the main LMW thiol involved in detoxification and maintaining redox homeostasis (Liu et al. 2013; Newton and Fahey 2008; Van Laer et al. 2012). The redox-active sulfydryl group of MSH protects cells from ROS by directly scavenging free radicals and by serving as a cofactor for antioxidant enzymes such as mycothiol peroxidase (MPx) and methionine 
sulfoxide reductase A (MsrA), in conjunction with mycoredoxin 1 (Mrx1) (Si et al. 2015a, b). Another mechanism is to use various antioxidative enzymes, including directly ROS-scavenging terminal enzymes such as catalase (KatG), superoxide dismutases (SOD), and peroxidase, oxidized proteins-repairing oxidoreductases, as well as regulatory proteins (Dalle-Donne et al. 2008).

Oxidized proteins-repairing oxidoreductases, such as thioredoxin (Trx), Mrx1, dithiol-disulfide isomerase (DsbA), DsbA-like Mrx1, and alkyl hydroperoxide reductase subunit D (AhpD), are believed to play a pivotal role in protecting against oxidative stress, maintaining intracellular thiol homeostasis, ensuring the proper folding of proteins and facilitating appropriate functioning of proteins in bacteria (Dalle-Donne et al. 2008; Su et al. 2019; Van Laer et al. 2012; Rosado et al. 2017). Mrx1 with the Cys-Pro-Tyr-Cys (C-P-Y-C) motif, an MSHdependent disulfide oxidoreductase with a glutaredoxin-like sequence and function, reduces mixed disulfides between $\mathrm{MSH}$ and $\mathrm{C}_{\mathrm{P}}$ of peroxidase with $\mathrm{N}$-terminal cysteine of the active site via 1-Cys monothiol mechanism. Mrx1 is kept reduced with an NADPH-dependent flavoenzyme mycothione reductase (Mtr), MSH, and NADPH (Van Laer et al. 2012). DsbA with the Cys-Pro-His-Cys (C-P-H-C) motif usually acts as an oxidase that catalyzes the oxidative refolding of RNase I (Greiner-Stoeffele et al. 1996). Recently, Rosado et al. (2017) found C. glutamicum NCgl2339 with the Cys-Pro-Phe-Cys (C-P-F-C) motif and Mycobacterium tuberculosis Rv2466c with the Cys-Pro-Trp-Cys (C-P-W-C) motif had the activity of demycothiolating and reducing a mycothiol arsenate adduct. NCg12339 and Rv2466c have no oxidase properties like classic DsbAs. Moreover, their kinetic properties were different from those of classic Mrx1. Therefore, Rosado et al. believed NCg12339 and Rv2466c were novel oxidoreductases, belonging to DsbA-like Mrx1. However, some aspects of this new type of oxidoreductase are poorly understood so far, such as their mode of action, actual enzymatic functioning, and biological function. Thus, an in-depth analysis of the physiological and biochemical characteristics and catalytic mechanisms is vital. Bioinformatics analysis reveals that $C$. glutamicum $\mathrm{NCg} 12478$ preserves the $\mathrm{C}-\mathrm{P}-\mathrm{F}-\mathrm{C}$ active-site sequence motif, similar to that of $\mathrm{NCgl} 2339$. The phenomenon indicated NCgl2478 may be a potentially new redox enzyme and protect C. glutamicum from oxidative stress. In this study, we selected ORF NCgl2478 and sought to explore the physiological and biochemical functions of $\mathrm{NCgl} 2478$ in C. glutamicum, paving the way for correctly classifying similar enzymes from other organisms.

\section{Material and methods}

\section{Bacterial strains and growth conditions}

The bacterial strains and plasmids used in this study were listed in Table 1. C. glutamicum RES167 strains used in this study were derived from the sequenced strain ATCC 13032. Escherichia coli JM109 (Stratagene, United States) and C. glutamicum RES167 strains were grown on either Luria-Bertani (LB) broth or LB agar plates at 37 and $30{ }^{\circ} \mathrm{C}$ under vigorous agitation $(220 \mathrm{rpm})$ as previously reported, respectively (Shen et al. 2005). To produce and maintain mutant of a gene in C. glutamicum, brain-heart broth medium containing $0.5 \mathrm{M}$ sorbitol (BHIS) was used (Shen et al. 2005). ncgl2478 gene in-frame deletion was generated using the method described (Shen et al. 2005). For complementation, the pXMJ19-ncgl2478 derivatives were transformed into $\Delta n c g l 2478$ mutant by electroporation. The transformant was selected on nalidixic acid and chloramphenicol-containing LB plates and its expression in C. glutamicum was induced by adding $0.5 \mathrm{mM}$ isopropyl $\beta$-D-1-thiogalactopyranoside (IPTG) (Sigma-Aldrich) (Shen et al. 2005). Antibiotics were added at the following concentrations: kanamycin, $50 \mu \mathrm{g} \mathrm{ml}^{-1}$ for E. coli and $25 \mu \mathrm{g} \mathrm{ml}^{-1}$ for C. glutamicum; nalidixic acid, $40 \mu \mathrm{g} \mathrm{ml}^{-1}$ for C. glutamicum; chloramphenicol, $20 \mu \mathrm{g} \mathrm{ml}^{-1}$ for E. coli and $10 \mu \mathrm{g} \mathrm{ml}^{-1}$ for C. glutamicum.

\section{Plasmid construction}

Primers used in this study were listed in Table 2. The ncgl2478 gene region of $C$. glutamicum was amplified with primer pair ONCg12478-F and ONCgl2478-R from genomic DNA of C. glutamicum RES167 by PCR, and then the resulting fragments cut with BamHI and HindIII enzymes were cloned into appropriately digested pET28a to give plasmids pET28a- $n$ cgl2478. The suicide plasmid pK18mobsacB- $\Delta n c g l 2478$ was obtained by two-step recombination as described previously (Su et al. 2018). To prepare pXMJ19-ncgl2478, primer pair CNCgl2478-F/CNCg12478$\mathrm{R}$ was used to amplify the $n c g l 2478$ gene DNA fragments from C. glutamicum genomic DNA. The resulting DNA fragments were cut and then cloned into similar digested pXMJ19. To generate pET28a-ncgl2478:C21S or pET28ancgl2478:C24S, site-directed mutagenesis was performed by two rounds of PCR as described (Si et al. 2015a, 2018a). To obtain the lacZY fusion reporter vector $\mathrm{pK} 18$ mobsacB$P_{n c g l 2478}: l a c Z Y$, overlap PCR was performed to fuse the $n c g l 2478$ promoter to the lacZY reporter gene ( $\mathrm{Su}$ et al. 2018). For obtaining pK18mobsacB- $P_{n c g l 2478 M}:$ lacZY, 258-bp ncgl2478 promoter DNA containing the mutagenized sequence of the predicted stress-responsive 
Table 1 Bacterial strains and plasmids used in this study

\begin{tabular}{|c|c|c|}
\hline Strains or plasmids & Relevant genotype description & Source or references \\
\hline \multicolumn{3}{|l|}{ Strains } \\
\hline \multicolumn{3}{|l|}{ Corynebacterium glutamicum } \\
\hline RES167 & Restriction-deficient mutant of ATCC13032, $\Delta(\operatorname{cglIM}-c \mathrm{glIR}-\mathrm{cglIIR})$ & Tauch et al. (2002) \\
\hline$\Delta n c g l 2478$ & $n c g l 2478$ deleted in RES167 & This study \\
\hline$\Delta \operatorname{sig} H$ & & Si et al. (2014a) \\
\hline \multicolumn{3}{|l|}{ E. coli } \\
\hline BL21(DE3) & $\begin{array}{l}\text { E. coli expression host, hsdS gal ( } \lambda \text { cIts857 ind-l Sam7 nin-5 lac UV5-T7 } \\
\text { gene 1) }\end{array}$ & Novagen \\
\hline JM109 & $\begin{array}{l}\text { recA1 supE44 endA1 hsdR17 gyrA96 relA1 thi } \Delta(\text { lac-proAB }) \mathrm{F}^{\prime}(\text { traD36 } \\
\left.\text { proABlacI }{ }^{\mathrm{q}} \text { lac } \Delta \mathrm{ZM15}\right)\end{array}$ & Stratagene (catalog no. 200235) \\
\hline \multicolumn{3}{|l|}{ Plasmids } \\
\hline pK18mobsacB & $\begin{array}{l}\text { Suicide plasmid carrying } s a c B \text { for selecting double crossover in } C \text {. glutami- } \\
\text { cum } \mathrm{Km}^{\mathrm{r}}\end{array}$ & Schäfer et al. (1994) \\
\hline pK18mobsacB- $\Delta n c g l 2478$ & Construct used for in-frame deletion of $n c g l 2478$ & This study \\
\hline pK18mobsacB- $P_{n c g l 2478}:: l a c Z Y$ & $P_{n c g l 2478}:: l a c Z Y$ fusion in $\mathrm{pK} 18 m o b s a c B$ & This study \\
\hline pXMJ19 & Shuttle vector $\left(P_{\text {tac }}\right.$ lacI $I^{q} p B L 1$ ori $V_{C . \text { glutamicum }} \mathrm{pK} 18$ ori $\left.V_{E . \text { coli }}\right)$ & Jakoby et al. (1999) \\
\hline pXMJ19-ncgl2478 & ncgl2478 cloned into pXMJ19 for complementation & This study \\
\hline pET28a & Expression vector with $\mathrm{N}$-terminal hexahistidine affinity tag & Novagen \\
\hline pET28a-ncgl2478 & $n c g l 2478$ in $\mathrm{pET} 28 \mathrm{a}$ & This study \\
\hline pET28a-ncgl2478:C21S & $n c g l 2478: C 21 S$ in $\mathrm{pET} 28 \mathrm{a}$ & This study \\
\hline pET28a-ncgl2478:C24S & ncgl2478: $C 24 S$ in pET28a & This study \\
\hline pET28a-mrxl & & Si et al. (2014b) \\
\hline pET28a-mrx1:C15S & & Si et al. (2014b) \\
\hline pET28a-mtr & & Si et al. (2014b) \\
\hline pET28a-trx & & Si et al. (2014b) \\
\hline pET28a-trxR & & Si et al. (2014b) \\
\hline pET28a-sigH & & Si et al. (2014a) \\
\hline
\end{tabular}

extra-cytoplasmic function-sigma $(\mathrm{ECF}-\sigma)$ factor SigH binding site $\left(P_{n c g l 2478 M}\right)$ was first directly synthesized by Shanghai Biotechnology Co., Ltd. Start and stop sites of $P_{n c g l 2478 M}$ were the same as those of $P_{n c g l 2478}$ in $P_{n c g l 2478}:$ lacZY. Then, the resulting 258-bp $P_{n c g l 2478 M}$ was fused to a $l a c Z Y$ reporter gene. Finally, $P_{n c g l 2478 M}: \because$ lacZ was inserted into similarly digested pK18mobsacB. The fidelity of all constructs was confirmed by DNA sequencing (Sangon Biotech, Shanghai, China).

\section{Overexpression and purification of recombinant protein}

pET28a derivatives were transformed into $E$. coli BL21(DE3) cells and recombinant proteins were purified as described previously (Si et al. 2018b). Eluted recombinant $\mathrm{His}_{6}-\mathrm{NCg} 12478$ proteins were concentrated and loaded onto a Superdex-75 10/300 gel filtration column (GE Healthcare, Piscataway, NJ) with a running condition of $10 \mathrm{mM}$ Tris (pH 7.4), $100 \mathrm{mM} \mathrm{NaCl}$, and $5 \mathrm{mM}$ $\beta$-mercaptoethanol. For conducting subsequent enzyme activity experiments, the $\mathrm{His}_{6}$ tag in protein was cut in the presence of 10 units of Enterokinase-Max (Invitrogen, Karlsruhe, Germany) at $4{ }^{\circ} \mathrm{C}$ overnight. To remove the cleaved tag and uncleaved protein, Ni-NTA agarose was used. All enzymes were purchased from Sigma-Aldrich (St. Louis, MO). Resulting $\mathrm{His}_{6}$-tag-free protein was dialyzed against $\mathrm{PBS}$ at $4{ }^{\circ} \mathrm{C}$ and concentrated for further experiments [ $>95 \%$ purity as estimated by sodium dodecyl sulfate-polyacrylamide gel electrophoresis (SDS-PAGE)].

\section{Agar-based disk diffusion assay}

Disk diffusion assays were performed for alkylating agents and oxidative agents according to Rawat et al. (2002). Briefly, bacterial strains were grown to the mid$\log$ phase and $100 \mu \mathrm{l}$ of culture containing about $10^{7} \mathrm{CFU}$ was spread onto $20 \mathrm{ml}$ LB agar plates. Paper disks soaked with $10 \mu \mathrm{l}$ of a stock solution of reagents were placed on top of the agar. Stock solutions were $50 \mathrm{mM}$ hydrogen peroxide $\left(\mathrm{H}_{2} \mathrm{O}_{2}\right), 5.5 \mathrm{mM}$ cumene hydroperoxide ( $\left.\mathrm{CHP}\right)$, 
Table 2 Primers used in this study

\begin{tabular}{|c|c|c|}
\hline Primiers & $5^{\prime}-3^{\prime}$ sequence & \\
\hline Cncgl2478-F1 & CCCAAGCTTATGTCTATTGAATTCTCCGCAC (HindIII) & For cloning $n c g l 2478$ wild type and mutants into pXMJ19 \\
\hline Cncgl2478-R1 & CGCGGATCCTTAGTTGCAGGTGCCGTCGACG $($ BamHI) & \\
\hline Oncg12478-F & CGCGGATCCATGTCTATTGAATTCTCCGCAC (BamHI) & For cloning $n c g l 2478$ wild type and mutants into pET28a \\
\hline Oncgl2478-R & CCCAAGCTTTTAGTTGCAGGTGCCGTCGACG (HindIII) & \\
\hline Dncg12478-F1 & $\begin{array}{l}\text { GGAAGATCTCTATGACATGATTACGAATTCGTGATG } \\
\text { ATTTCCGGTTCGTCGAC }(B g l \text { III })\end{array}$ & To generate pK18mobsacB- $\Delta$ ncgl2478 \\
\hline Dncg12478-R1 & CCGATGTAGCAGAAGGGGCACATG & \\
\hline Dncg12478-F2 & $\begin{array}{l}\text { CATGTGCCCCTTCTGCTACATCGGCAGCCCATTTGA } \\
\text { GGTCATTGAC }\end{array}$ & \\
\hline Dncg12478-R2 & $\begin{array}{l}\text { ACGCGTCGACTGCTTGGTATTCAAAAAGATCCAC } \\
\text { (SalI) }\end{array}$ & \\
\hline Oncg12478-C21S-F & GGAGCGACATCATGAGCCCCTTCTGCTAC & To generate $n c g l 2478: C 21 S$ DNA fragment \\
\hline Oncgl2478-C21S-R & GTAGCAGAAGGGGCTCATGATGTCGCTCC & \\
\hline Oncgl2478-C24S-F & GACATCATGTGCCCСТTCAGCTACATCGGCAAAAAG & To generate $n c g l 2478: C 24 S$ DNA fragment \\
\hline Oncgl2478-C24S-R & CTTTTTGCCGATGTAGCTGAAGGGGCACATGATGTC & \\
\hline Pncgl2478-F & TCCCCCGGGATCTTAAGTACCCCTGTTTTGGAG (SmaI) & To generate pK18mobsacB-P $P_{n c g l 2478}:$ lacZY and the 258 - \\
\hline$P_{n c g l 2478}-\mathrm{R}$ & ACTAGTTAGCCCATGCACCACGATAACGCG (SpeI) & bp ncgl2478 promoter \\
\hline lacZY-F1 & $\begin{array}{l}\text { CGCGTTATCGTGGTGCATGGGCTAACTAGT ATGACC } \\
\text { ATGATTACGGATTC }(\text { SpeI })\end{array}$ & \\
\hline lacZY-R & AAAACTGCAGTTAAGCGACTTCATTCACCTG(PstI) & \\
\hline Qncgl2478-F & CGCCAAATGAACGGCCAAGTCC & RT-PCR \\
\hline Qncgl2478-R & GGCTTTCGCGAAGTGGGTAAGG & \\
\hline Encgl2478-F & GTACCCCTGTTTTGGAGAATGC & To produce the 211-bp EMSA promoter DNA \\
\hline Encgl2478-R & CGTCTCCTTGCAATGTGAACCC & \\
\hline Control-F & TGACGAAACCATCGCGGCCAACAC & To produce the 211-bp EMSA control DNA \\
\hline Control-R & CACGTCGGATTCGAGAGCTTCGCG & \\
\hline $16 \mathrm{~S}$ rRNA-F & ACCCTTGTCTTATGTTGCCAG & RT-PCR \\
\hline $16 \mathrm{~S}$ rRNA-R & TGTACCGACCATTGTAGCATG & \\
\hline F1-F & GGCCGTTCATTTGGCGGGCCTGCTC & Co-transcription \\
\hline F1-R & CCAAAATAACCTGGGGTTTCCTCGC & \\
\hline
\end{tabular}

Underlined sites indicated restriction enzyme cutting sites added for cloning. Letters in italic denoted the mutation sites in overlap PCR for sitedirected mutation

$0.2 \mathrm{mM}$ sodium hypochlorite $(\mathrm{NaClO}), 5 \mathrm{mM}$ diamide, $50 \mathrm{mM}$ 2, 4-dinitrochlorobenzene (DNCB), and $0.6 \mathrm{mM}$ iodoacetamide (IAM). The disks were allowed to dry and the plates were incubated for $2-3$ days at $30^{\circ} \mathrm{C}$. The diameter of the inhibition zones was measured. Experiments were performed in triplicate.

\section{Electrophoretic mobility shift assay (EMSA)}

EMSA was performed according to the method described previously ( $\mathrm{Su}$ et al. 2019).

\section{Preparation of oxidized NCg/2478-S in vitro}

Oxidized $\mathrm{NCg} 12478-\mathrm{S}_{2}$ was prepared according to previously described (Van Laer et al. 2012; Pedre et al. 2015) protocol. First, NCg12478 or Mrx1 from C. glutamicum was reduced by incubation with $50 \mathrm{mM}$ DTT for $30 \mathrm{~min}$ at room temperature. Second, excess DTT was removed by ultrafiltration. Third, pre-reduced NCg12478 or Mrx1 was oxidized with a fivefold molar excess of diamide and incubated for $30 \mathrm{~min}$ at room temperature. Finally, oxidized $\mathrm{NCgl} 2478-\mathrm{S}_{2}$ or $\mathrm{Mrx} 1-\mathrm{S}_{2}$ was purified on a Superdex 75 10/300 GL column (GE Healthcare) equilibrated with $20 \mathrm{mM}$ Tris, $150 \mathrm{mM} \mathrm{NaCl}$, pH 7.6 for further experiments. Pure NCgl2478-S 2 and Mrx1-S 2 were confirmed by MatrixAssisted Laser Desorption/Ionization Time of Flight Mass Spectrometry (MALDI-TOF MS).

\section{Steady-state kinetics of oxidized NCg/2478-S by Trx/TrxR/NADPH and MSH/Mtr/NADPH pathway}

Oxidized $\mathrm{NCg} 12478-\mathrm{S}_{2}$-dependent oxidation of $\mathrm{NADPH}$ in the Trx/TrxR/NADPH or MSH/Mtr/NADPH pathway was 
continuously monitored at $340 \mathrm{~nm}\left(\varepsilon_{340}=\right.$ of $\left.6220 \mathrm{M}^{-1} \cdot \mathrm{cm}^{-1}\right)$ in reaction mixture. In the Trx/TrxR/NADPH pathway, the reaction mixture contained $50 \mathrm{mM}$ Tris- $\mathrm{HCl}$ buffer $(\mathrm{pH}$ 7.5), $1 \mathrm{mM}$ EDTA, $5 \mu \mathrm{M}$ C. glutamicum TrxR, $300 \mu \mathrm{M}$ $\mathrm{NADPH}, 5 \mu \mathrm{M} C$. glutamicum Trx, and varying concentrations of oxidized NCg12478-S ${ }_{2}$. In the MSH/Mtr/NADPH pathway, reaction mixture contained $50 \mathrm{mM}$ Tris- $\mathrm{HCl}$ buffer (pH 7.5), 1 mM EDTA, $5 \mu \mathrm{M}$ C. glutamicum Mtr, $300 \mu \mathrm{M}$ $\mathrm{NADPH}, 500 \mu \mathrm{M} \mathrm{MSH}$, and varying concentrations of oxidized NCgl2478-S $\mathrm{S}_{2}$. All reactions were carried out at $37{ }^{\circ} \mathrm{C}$ and started with the addition of oxidized $\mathrm{NCgl} 2478-\mathrm{S}_{2}$ in a reaction mixture previously incubated for $3 \mathrm{~min}$ at $37^{\circ} \mathrm{C}$. Control measurements were performed in the absence of

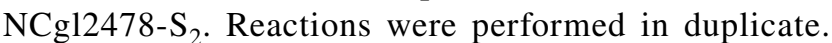
Mrx1-S $\mathrm{S}_{2}$ was used as a positive control. The $k_{\text {cat }}$ and $K_{\mathrm{m}}$ values were obtained from a non-linear fit with the Michaelis-Menten equation using the program GraphPad Prism 5.

\section{Quantitative analysis of sulfhydryl groups}

Free sulfhydryl groups in wild-type NCgl2478 (NCg12478 WT) and its variants were measured using 5, 5'-dithio-bis (2-nitrobenzoic acid) (DTNB) (Ellman 1959). The amounts of reactive sulfhydryl groups were measured using the molar absorption coefficient of TNB at $412 \mathrm{~nm}\left(\varepsilon_{412}\right)$ of $13,600 \mathrm{M}^{-1} \cdot \mathrm{cm}^{-1}$ (Gething and Davidson 1972).

\section{NBD-Cl analysis of the sulfenic acid state}

To study the formation of cysteine sulfenic acid (Cys-SOH) as a reaction intermediate, $\mathrm{NCgl2478:C21S} \mathrm{and}$ NCg12478:C24S labeled with 4-chloro-7-nitrobenzofurazan (NBD-Cl) were assayed as described previously (Selles et al. 2012).

\section{Enzymatic activity assay}

Insulin disulfide reduction was performed based on the method described by Rosado et al. (2017). The precipitation starting point was defined as an increase of 0.02 absorbance units at $A_{600}$ after a stable baseline recording and the rate of precipitation was calculated using a linear regression composed of $A_{600}$ ranging from 2000 to $2500 \mathrm{~s}$ (Holmgren 1979).

Hydroxyethyl disulfide (HED) was utilized to prepare and measure the mixed disulfide between MSH and 2-hydroxyethyl disulfide (HED) (HED-SSM) reduction activity (Si et al. 2019). HED-SSM was formed by incubating $1000 \mathrm{mM}$ HED with $50 \mathrm{mM} \mathrm{MSH}$ at $30^{\circ} \mathrm{C}$ for $3 \mathrm{~min}$. Briefly, the kinetic parameters were determined in the presence of varying concentrations of HED-SSM $(0-20 \mathrm{mM})$. The enzyme reactions were measured in $50 \mathrm{mM}$ potassium phosphate buffer $(\mathrm{pH}$ 7.6), $250 \mu \mathrm{M}$ NADPH, $5 \mu \mathrm{M}$ Mtr, $500 \mu \mathrm{M} \mathrm{MSH}$, and $1 \mu \mathrm{M}$ $\mathrm{NCgl} 2478$ (WT, C21S, or C24S). The assay was performed at $25{ }^{\circ} \mathrm{C}$. Absorption was monitored at $340 \mathrm{~nm}$. The activity was determined after subtracting the spontaneous reduction rate observed in the absence of $\mathrm{NCgl} 2478$ and the number of micromoles of NADPH oxidized per second per micromole of enzyme (i.e. the turnover number, $\mathrm{s}^{-1}$ ) was calculated using the molar absorption coefficient of NADPH at $340 \mathrm{~nm}$ $\left(\varepsilon_{340}\right)$ of $6220 \mathrm{M}^{-1} \cdot \mathrm{cm}^{-1}$. Three independent experiments were performed at each substrate concentration. The $k_{\text {cat }}$ and $K_{\mathrm{m}}$ values of NCgl2478 for HED-SSM substrates were obtained from a non-linear fit with the Michaelis-Menten equation using the program GraphPad Prism 5. Mrx1 was used as a control.

\section{pKa determination}

The extinction coefficient of thiol groups (R-SH) at $240 \mathrm{~nm}$ was the main readout utilized to measure $\mathrm{p} K a$ values of cysteine residues due to the lack of absorption of its unionized counterpart $\left(\mathrm{R}-\mathrm{S}^{-}\right)$in the same wavelength (Roos et al. 2013). To cover a broad $\mathrm{pH}$ range, a reaction mixture containing a poly-buffer solution composed of $10 \mathrm{mM}$ sodium acetate, $10 \mathrm{mM}$ sodium phosphate, $10 \mathrm{mM}$ sodium borate, and $10 \mathrm{mM}$ sodium citrate, $\mathrm{pH}$ 9.4, was used. For the oxidation of cysteine mutants, a tenfold excess of $\mathrm{H}_{2} \mathrm{O}_{2}$ was used. Excess $\mathrm{H}_{2} \mathrm{O}_{2}$ was removed by ultrafiltration. A final reaction mixture of $20 \mu \mathrm{M} \mathrm{NCg12478} \mathrm{(reduced} \mathrm{or} \mathrm{oxidized)}$ was titrated with $100 \mathrm{mM} \mathrm{HCl}$. The $\mathrm{pKa}$ of $\mathrm{NCgl} 2478: \mathrm{C} 22 \mathrm{~S}$ and NCg12478:C24S variants were determined in the same conditions as described for $\mathrm{NCgl} 2478 \mathrm{WT}$. The measurements were performed in a Carry UV spectrophotometer (Agilent Technologies) precooled to $10{ }^{\circ} \mathrm{C}$. The sigmoidal pH-dependent saturation curve was fitted to the HendersonHasselbalch equation (Roos et al. 2007), where $A_{\exp }$ was the experimental value $A_{240} / A_{280}, A_{\mathrm{SH}}$ was the $A_{240} / A_{280}$ value for the protonated form, and $A_{\mathrm{S}}{ }^{-}$is the $A_{240} / A_{280}$ for the deprotonated form. The data were fitted to the following equation using GraphPad Prism version 5 (San Diego California USA).

$A_{\text {exp }}=A_{\mathrm{SH}}+\frac{\left(A_{\mathrm{S}^{-}}-A_{\mathrm{SH}}\right)}{1+10^{\left(p \mathrm{~K}_{\mathrm{a}}-\mathrm{pH}\right)}}$

\section{RNase I activity assay}

Oxidase activity was measured as described previously (Roos et al. 2007).

\section{Construction of chromosomal fusion reporter strains and $\beta$-Galactosidase assay}

The lacZY fusion reporter plasmid pK18mobsacB$P_{n c g l 2478}:: l a c Z Y$ was transformed into the corresponding 
C. glutamicum RES 167 strain by electroporation and the chromosomal fusion reporter strains were selected on LB agar plates supplemented with kanamycin (Si et al. 2019). The resulting strains were grown in LB medium to an optical density at $600 \mathrm{~nm}$ of $0.6-0.7$ and then treated with different reagents of various concentrations at $30{ }^{\circ} \mathrm{C}$ for $30 \mathrm{~min}$. $\beta$-Galactosidase activity was assayed with $O$-nitrophenyl- $\beta$ D-galactopyranoside (ONPG) as the substrate (Miller 1992). The $\beta$-Galactosidase data presented were the averages of three independent biological experiments and error bars indicated the SDs from three independent experiments.

\section{Quantitative real-time polymerase chain reaction (qRT-PCR) analysis}

Isolation of the total RNA and transcript levels analysis was performed as described previously (Si et al. 2019). To obtain standardized results, the relative abundance of the 16S rRNA gene was used as the internal standard.

\section{Statistical analysis}

The results shown represented the average of three independent experiments; error bars indicated the standard deviation (SD) from three independent experiments. Statistical analyses of survival rate, transcription level, and protein level were determined with paired two-tailed Student's $t$ test. GraphPad Prism Software was used to carry out statistical analyses (GraphPad Software).

\section{Results and discussion}

\section{C. glutamicum NCgl2478 null mutant was sensitive to oxidative stress}

C. glutamicum NCg12478 containing the Cys-Pro-Phe-Cys (C-P-F-C) motif is annotated as a dithiol-disulfide isomerase DsbA. Recently, a demonstration indicated that Rv2466c from M. tuberculosis and NCg12339 from C. glutamicum, having high sequence similarity to DsbA, belong to a novel DsbA-Mrx1 cluster (Rosado et al. 2017). The novel DsbA-Mrx1 cluster has the special Cys-Pro-Trp/Phe-Cys (C-P-W/F-C) activesite sequence motif and exhibits different enzymatic features and substrate preferences from Mrx 1 cluster with the catalytic motif Cys-Pro-Tyr-Cys (C-P-Y-C) or classical DsbA cluster with the catalytic motif Cys-Pro-His-Cys (C-P-H-C) (Rosado et al. 2017). Although amino acid sequence comparison revealed $\mathrm{NCgl} 2478$ is only $29.8 \%$ identical to Rv2466c and $26.2 \%$ identical to $\mathrm{NCg} 12339$ (Fig. 1a), we presumed it might be also a member of the DsbA-Mrx1 cluster involved in stress response as it shared the $\mathrm{C}-\mathrm{P}-\mathrm{F}-\mathrm{C}$ signature motif presumed to be an exclusive characteristic of the DsbA-Mrx 1 cluster (Fig. 1b). M. tuberculosis Rv2466c is validated to promote mycobacterial resistance to oxidative stress (Rosado et al. 2017). Thus, to assess the role of NCg12478 in protecting cells against oxidative stress, we constructed an ncgl2478 null mutant in $C$. glutamicum and tested the sensitive phenotype of ncgl2478 mutant to various oxidizing and $\mathrm{H}_{2} \mathrm{O}_{2}$-inducing agents [hydrogen peroxide $\left(\mathrm{H}_{2} \mathrm{O}_{2}\right)$, cumene hydroperoxide (CHP), sodium hypochlorite $(\mathrm{NaClO})$, diamide, 2, 4-dinitrochlorobenzene (DNCB), and iodoacetamide (IAM)] by an agar-based disc diffusion assay. As shown in Table 3, $\Delta n c$ gl2478 strain

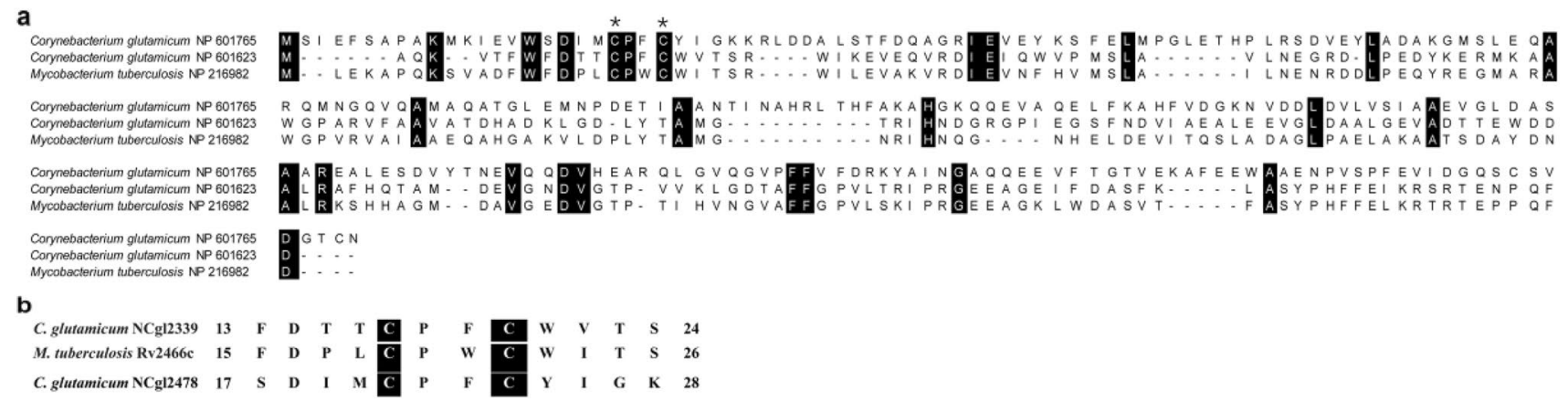

Fig. 1 Multiple sequence alignment of NCg12478 with Rv2466c from M. tuberculosis and NCgl2339 from C. glutamicum. a Active site Cys was pointed out by a black star. Reference sequences were retrieved from the NCBI Database, including C. glutamicum ATCC NCgl2478 (NP_601765), C. glutamicum ATCC NCgl2339 (NP_601623); Myco- bacterium tuberculosis Rv2466c (NP_216982). b Sequence alignment between active-site cysteines in $\mathrm{NCgl} 2478$ and Rv2466c from M. tuberculosis or NCgl2339 from C. glutamicum. Magenta highlights the dicysteine motif 
Table 3 Sensitivity of $C$. glutamicum strains to oxidizing agents tested by disk diffusion assay

\begin{tabular}{llll}
\hline Agents & \multicolumn{3}{l}{$\begin{array}{l}\text { Size of growth inhibition zone }(\mathrm{cm}) \text { of various } \\
\text { strains }{ }^{\mathrm{a}}\end{array}$} \\
\cline { 2 - 4 } & WT & $\Delta n c g l 2478$ & $\Delta n c g l 2478^{+}$ \\
\hline $\mathrm{H}_{2} \mathrm{O}_{2}$ & $1.5 \pm 0.3$ & $2.7 \pm 0.5^{* *}$ & $1.6 \pm 0.2$ \\
$\mathrm{CHP}$ & $1.8 \pm 0.3$ & $2.3 \pm 0.4^{*}$ & $1.7 \pm 0.4$ \\
$\mathrm{NaClO}$ & $2.7 \pm 0.2$ & $3.2 \pm 0.3^{*}$ & $2.8 \pm 0.4$ \\
Diamide & $1.4 \pm 0.3$ & $1.8 \pm 0.2^{*}$ & $1.5 \pm 0.2$ \\
DNCB & $1.6 \pm 0.2$ & $2.1 \pm 0.3^{*}$ & $1.7 \pm 0.4$ \\
IAM & $1.7 \pm 0.4$ & $2.2 \pm 0.3^{*}$ & $1.7 \pm 0.2$ \\
\hline
\end{tabular}

$\mathrm{H}_{2} \mathrm{O}_{2}$ hydrogen peroxide, $\mathrm{CHP}$ cumene hydroperoxide, $\mathrm{NaClO}$ sodium hypochlorite, $D N C B$ 2,4-dinitrochlorobenzene, IAM iodoacetamide

${ }^{*} P \leq 0.05$ or $* * P \leq 0.01$ versus WT for the $\Delta n c g l 2478$ mutant

${ }^{\text {a }}$ The values were mean \pm SD for three independent determinations

(the mutant lacking $n c g l 2478$ with the empty plasmid pXMJ19) showed decreased resistance to all chemical reagents tested challenge compared to the WT strain (the C. glutamicum RES167 strain with the empty plasmid pXMJ19), giving a significantly larger zone of inhibition than WT strain. To confirm that the sensitivity to reagents may occur when lacking ncgl2478, complementary strain $\Delta n c g l 2478^{+}$was constructed by the introduction of plasmid pXMJ19 in trans containing the wild-type $C$. glutamicum ncgl 2478 gene into ncgl2478 null mutant. As shown in Table 3, sensitive phenotypes were almost fully restored in $\Delta n c g l 2478^{+}$. Although deletion of $n c g l 2478$ did not affect $C$. glutamicum growth under normal condition, $\mathrm{NCgl} 2478$ was important for survival under various oxidative stress conditions.

\section{Formation of an intramolecular disulfide bond Cys21-Cys24 under oxidative stress}

The Cys in the Cys ${ }^{19}$-Pro-Trp-Cys ${ }^{22}\left(\mathrm{C}^{19}-\mathrm{P}-\mathrm{W}-\mathrm{C}^{22}\right)$ active-site motif of $M$. tuberculosis Rv2466c could form Cys19-Cys22 disulfide and Cys19-MSH mixed disulfide under oxidative stress (Rosado et al. 2017). Moreover, Cys19 and Cys22 of M. tuberculosis Rv2466c were the nucleophilic and resolving cysteines, respectively. Amino acid sequence comparison showed that Cys 21 of NCg12478 might be the nucleophilic cysteine residue $\left(\mathrm{C}_{\mathrm{p}}\right)$ that had been reported to be involved in catalysis via the transient formation of a sulfenic acid (Cys-SOH) (Baker and Poole 2003) (Fig. 1a). However, Cys24 might be the resolving Cys residues $\left(C_{R}\right)$. During catalysis, the labile peroxidatic Cys- $\mathrm{SOH}$ is easily attacked by $\mathrm{C}_{\mathrm{R}}$ to form the redox-active disulfide. To trap $\mathrm{Cys}-\mathrm{SOH}$, the $\mathrm{C}$-terminal cysteine of the active-site disulfide pair must be removed. Therefore, to investigate whether Cys 21 and Cys 24 have the above speculative function and test if these two cysteine residues in $\mathrm{NCgl} 2478$ could undergo disulfide after oxidation, we mutated the first and the second cysteine of the CXXC motif to serine, and these two mutated proteins NCgl2478:C21S and NCgl2478:C24S were purified by the Ni-NTA His.Bind Resin. NCgl2478 WT, NCg12478:C21S and NCg12478:C24S with and without previous exposure to $\mathrm{H}_{2} \mathrm{O}_{2}$ were used to carry out the free thiol content analysis. As shown in Fig. 2a, the DTTtreated NCgl2478 WT contained $1.85 \pm 0.47$ thiol groups per monomer, but the thiol content decreased to $0.22 \pm 0.06$ when $\mathrm{NCgl} 2478 \mathrm{WT}$ was treated with $\mathrm{H}_{2} \mathrm{O}_{2}$. The difference of 1.63 thiol groups between the two preparations was linked to the full oxidation of $\mathrm{NCgl} 2478 \mathrm{WT}$ after $\mathrm{H}_{2} \mathrm{O}_{2}$ treatment. These data indicated that $\mathrm{NCg} 12478 \mathrm{WT}$ was fully oxidized by $\mathrm{H}_{2} \mathrm{O}_{2}$ to form a disulfide bond between Cys21 and Cys24. a

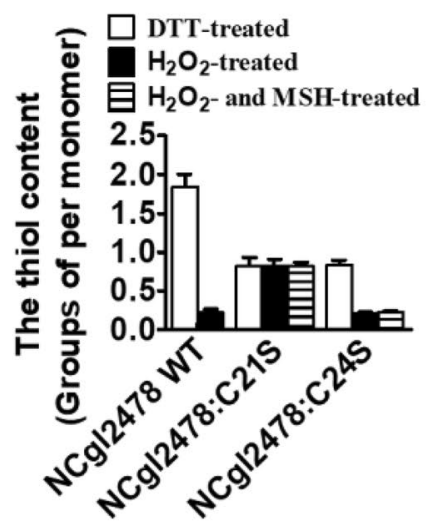

b

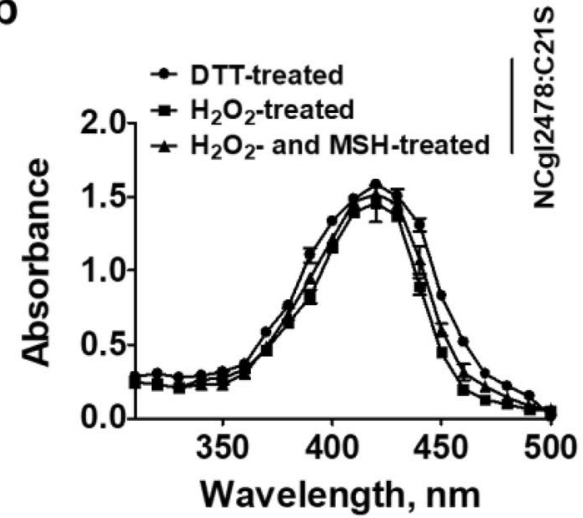

C

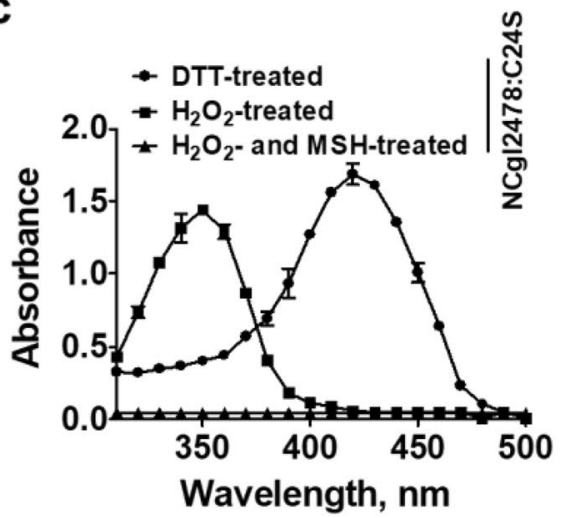

Fig. 2 The thiol content of DTT- or $\mathrm{H}_{2} \mathrm{O}_{2}$-treated $\mathrm{NCgl} 2478$. a Free sulfhydryl groups in $\mathrm{NCg} 12478$ WT and its variants were determined using 5, 5'-dithio-bis (2-nitrobenzoicacid) (DTNB). b, c Spectrophotometric analysis of NBD-labelled NCgl2478:C21S and
NCg12478:C24S. Reduced proteins treated with and without $\mathrm{H}_{2} \mathrm{O}_{2}$ or $\mathrm{H}_{2} \mathrm{O}_{2}$ and $\mathrm{MSH}$ were modified with NBD-Cl for $30 \mathrm{~min}$. The resulting proteins were analyzed spectrophotometrically at $200-600 \mathrm{~nm}$ 
NBD-Cl can exclusively react with free thiol groups in protein and protein sulfenic acids ( $\mathrm{P}-\mathrm{SOH})$, but not with protein sulfinic $\left(\mathrm{P}-\mathrm{SO}_{2} \mathrm{H}\right)$ and sulfonic $\left(\mathrm{P}-\mathrm{SO}_{3} \mathrm{H}\right)$ acid. The covalent attachment of NBD-Cl generated an absorption peak at $\sim 420 \mathrm{~nm}$ upon reaction with thiol groups, whereas it peaked at $\sim 347 \mathrm{~nm}$ upon reaction with sulfenic acids (Baker and Poole 2003). Following reaction with NBD-Cl, the absorption spectra of the NCg12478:C21S variants remained unchanged before and after exposure to $\mathrm{H}_{2} \mathrm{O}_{2}$ or $\mathrm{H}_{2} \mathrm{O}_{2}$ and $\mathrm{MSH}$, exhibiting only the $420 \mathrm{~nm}$ peak (Fig. 2b). DTNB assay for free thiol contents also showed one thiol per monomer before and after $\mathrm{H}_{2} \mathrm{O}_{2}$ or $\mathrm{H}_{2} \mathrm{O}_{2}$ and $\mathrm{MSH}$ treatment, implying no $\mathrm{SOH}$ is formed on Cys24, and Cys24 was still in thiol form under exposure to $\mathrm{H}_{2} \mathrm{O}_{2}$ or $\mathrm{H}_{2} \mathrm{O}_{2}$ and $\mathrm{MSH}$ (Fig. 2a). However, NCg12478:C24S under $\mathrm{H}_{2} \mathrm{O}_{2}$ treatment lost one thiol group, compared to the thiol content of DTT-treated state, indicating that Cys 21 did not exist as a thiol in $\mathrm{H}_{2} \mathrm{O}_{2}$-treated $\mathrm{NCgl} 2478$ :C24S variant (Fig. 2a). Consistently, $\mathrm{H}_{2} \mathrm{O}_{2}$-treated and NBDlabeled NCg12478:C24S had an absorbance maximum $\left(\lambda_{\max }\right)$ of $347 \mathrm{~nm}$, representing the NBD-modified product Cys-S(O)-NBD (Ellis and Poole 1997), which clearly signified the detection and trapping of $\mathrm{SOH}$ at $\mathrm{Cys} 21$, the only Cys in the NCg12478:C24S variant (Fig. 2c). However, non- $\mathrm{H}_{2} \mathrm{O}_{2}$-treated $\mathrm{NCg12478:C24S} \mathrm{modified} \mathrm{with} \mathrm{NBD-Cl}$ produced a new covalently attached spectral species with a $\lambda_{\max }$ of $420 \mathrm{~nm}$, consistent with previously characterized thiol adducts with NBD-Cl (Cys-S-NBD). Interestingly, no NBD-Cl labeling in $\mathrm{H}_{2} \mathrm{O}_{2}$-treated $\mathrm{NCg12478:C24S} \mathrm{occurred}$ in the presence of $\mathrm{MSH}$, indicating $\mathrm{MSH}$ reacted with NCg12478:C24S-SOH to form NCg12478:C24S-SSM (the mixed disulfide between MSH and NCgl2478:C24S). This result showed that Cys21 was sensitive to oxidant, forming a sulfenic acid (Cys21-SOH). In the presence of MSH, MSH directly interacted with Cys21-SOH to form Cys21-MSH mixed disulfide. Further, Cys24 resolved the Cys21-MSH mixed disulfide or Cys21-SOH, leading to the formation of a Cys21-Cys24 disulfide. This result agrees with what Rosado et al. reported for M. tuberculosis Rv2466c (Rosado et al. 2017).

\section{Oxidized NCgl2478 preferred the MSH/Mtr/NADPH pathway as an electron source}

To identify possible electron donor pathways coupled to $\mathrm{NCgl} 2478$ reduction, two of the most important electron transfer pathways in C. glutamicum responsible for keeping the redox potential in balance were reproduced in vitro, that of the MSH/Mtr/NADPH and Trx/TrxR/NADPH. To do so, $\mathrm{NCgl} 2478$ was first oxidized with a fivefold molar excess of diamide to obtain $\mathrm{NCgl} 2478-\mathrm{S}_{2}$ (NCg12478ox). $\mathrm{NCgl} 2478-\mathrm{S}_{2}$ with a single disulfide bond between its active site cysteines was added as a substrate for the two electron transfer pathways mentioned above to measure steady-state kinetics. As shown in Fig. $3 \mathrm{a}, \mathrm{b}$, the $K_{\mathrm{m}}$ value, $k_{\text {cat }}$ value, and catalytic coefficient of $\mathrm{NCgl} 2478-\mathrm{S}_{2}$ for the MSH/Mtr/ NADPH or the Trx/TrxR/NADPH electron donor pathway were calculated to be $1.01 \pm 0.07 \mu \mathrm{M}, 3.19 \pm 0.05 \mathrm{~s}^{-1}$, and $3.15 \pm 0.07 \times 10^{6} \mathrm{M}^{-1} \mathrm{~s}^{-1}$, or $20.05 \pm 4.69 \mu \mathrm{M}$, $0.52 \pm 0.04 \mathrm{~s}^{-1}$, and $2.57 \pm 0.38 \times 10^{4} \mathrm{M}^{-1} \mathrm{~s}^{-1}$, respectively. It is worth noting that reduction of the oxidized form of Mrx1 (Mrx1ox) through the MSH/Mtr/NADPH pathway resulted in a catalytic coefficient of $2.43 \times 10^{7} \mathrm{M}^{-1} \mathrm{~s}^{-1}$ (Fig. 3c), and Mrx1 has been shown previously not to use the Trx/TrxR/NADPH electron donor pathway (Van Laer et al. 2012). Here, we have clearly shown that although $\mathrm{NCg1} 2478$ ox could be reduced by both electron pathways, the enzyme was reduced about 120-times faster with the
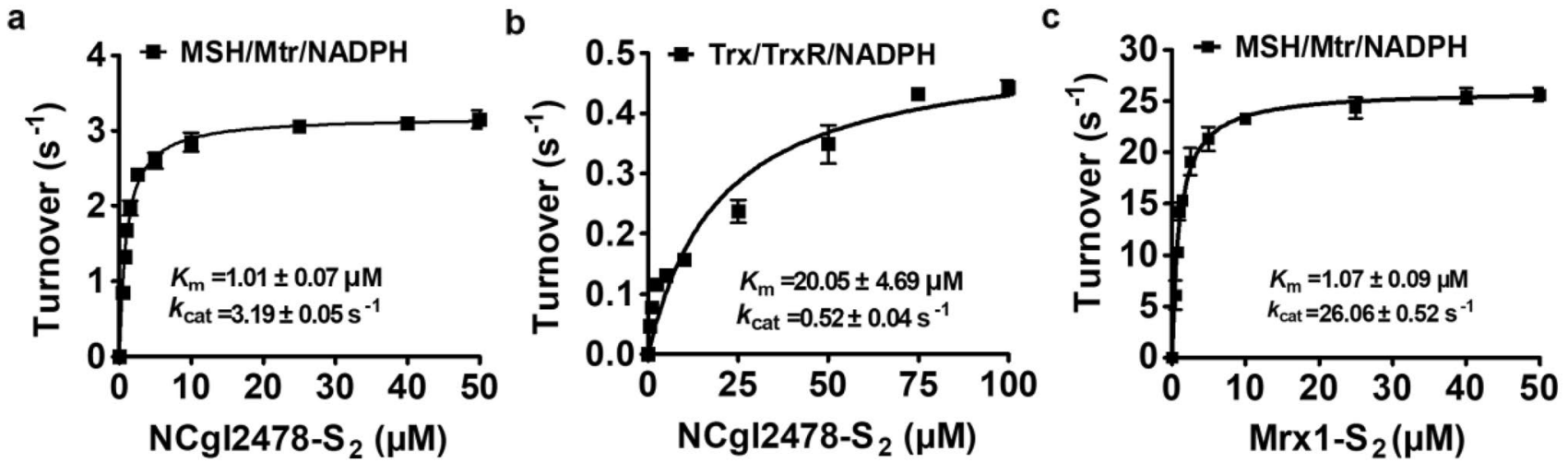

Fig. 3 Oxidized $\mathrm{NCgl} 2478-\mathrm{S}_{2}$ was reduced preferably by the MSH/ Mtr/NADPH pathway. The reduction of the oxidized NCgl2478- $\mathrm{S}_{2}$ (a) and $\mathrm{Mrx} 1-\mathrm{S}_{2}$ (c) by the MSH/Mtr/NADPH, or the reduction of the oxidized $\mathrm{NCgl} 2478-\mathrm{S}_{2}$ (b) by the $\operatorname{Trx} / \operatorname{TrxR} / \mathrm{NADPH}$ pathway was evaluated via Michaelis-Menten steady-state kinetics using the program GraphPad Prism 5. The data were represented as mean \pm SD of three independent experiments. Different concentrations of oxidized $\mathrm{NCg} 12478-\mathrm{S}_{2}$ or $\mathrm{Mrx} 1-\mathrm{S}_{2}$ were mixed with a pre-incubated mixture of the MSH, Mtr, and NADPH, or Trx, TrxR, and NADPH 
MSH/Mtr/NADPH pathway compared with the Trx/TrxR/ NADPH pathway, indicating NCgl2478ox prefers the MSH/ Mtr/MSH pathway. Mrx1ox catalyzed an approximately eightfold-faster reaction coupled to the MSH/Mtr/NADPH pathway compared with $\mathrm{NCgl} 2478 \mathrm{ox}$, indicating a different specificity of electron donor pathway for both enzymes (Fig. 3a, c).

\section{The $\mathrm{pKa}$ of the cysteine residues}

Since the thiolate ion has a higher absorption at $240 \mathrm{~nm}$ wavelength than the thiol group, the $\mathrm{pKa}$ of active site residues in $\mathrm{NCgl} 2478$ was therefore determined by recording the absorption at $240 \mathrm{~nm}$ during a $\mathrm{pH}$ titration (Roos et al. 2013). As shown in Fig. 4a, the pKa values of the nucleophilic Cys21 and the resolving Cys24 were less than 6 and 8.09 , respectively. The result indicated that the low $\mathrm{pKa}$ value made Cys 21 function as the nucleophilic Cys. In addition, the $\mathrm{pKa}$ value of nucleophilic Cys of $\mathrm{NCgl} 2478$ lied between the $\mathrm{p} K a$ values of the respective cysteines of Mrx 1 (6.8) and DsbA ( 3.5). Moreover, the $\mathrm{pKa}$ of the Cys24 (8.09) was already lower than the $\mathrm{pKa}$ of the MSH sulfur (8.76) (Sharma et al. 2016), which made Cys 24 more attack Cys21-MSH mixed disulfide, leading to the formation of a Cys21-Cys24 disulfide.

\section{NCgl2478 has no oxidase properties}

To test its putative DsbA-oxidoreductase activity, we used E. coli RNase I as a substrate. RNase I was active with its four disulfide bonds correctly formed, making it an ideal model enzyme for oxidative protein folding evaluation (Messens et al. 2007). We used methylene blue intercalated RNA as a substrate to check the RNase activity at $659 \mathrm{~nm}$ after the incubation of reduced unfolded RNase I with NCg12478 and Mrx1 (Greiner-Stoeffele et al. 1996). NCg12478 did not catalyze the oxidative refolding of RNase (Fig. 4b). Reduced RNase I (unfolded) demonstrated $15.5 \%$ of activity relative to folded RNase I (100\%). In contrast, in the presence of Mrx 1, 38.2\% of activity was recovered. Thus, NCgl2478 did not function as an oxidase.

\section{NCgl2478 reduced mycothiolated mixed disulfides preferably via a monothiol mechanism}

M. tuberculosis Rv2466c reduced mycothiolated mixed disulfides and intramolecular disulfide bonds coupled to the MSH/Mtr/NADPH pathway via a different mechanism (Rosado et al. 2017). This led us to survey what mechanism NCg12478 used to reduce mycothiolated mixed disulfides and intramolecular disulfide bonds coupled to the MSH/ Mtr/NADPH pathway. The functionalities of NCg12478 WT, NCg12478:C21S, and NCg12478:C24S to reduce insulin and the mixed disulfide between 2-hydroxyethyl disulfide (HED) and MSH (HED-SSM) were tested by following a

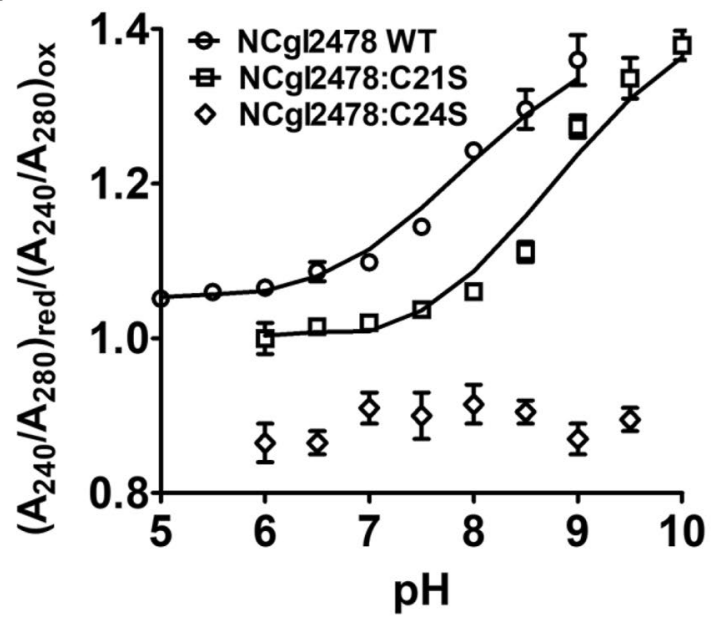

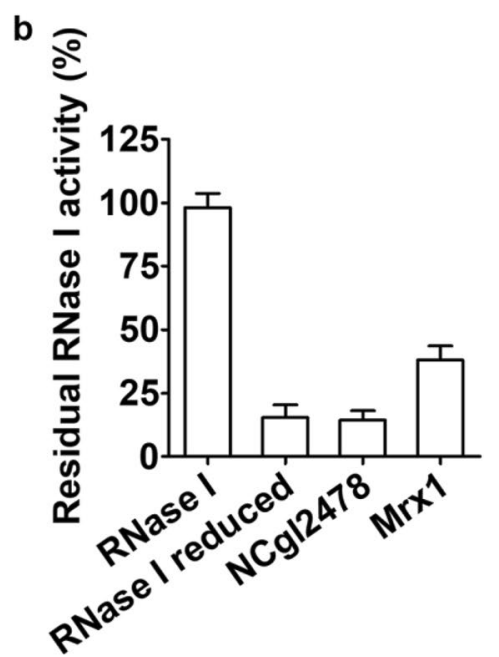

Fig. 4 The cysteine of NCg12478. a Cys21 was the nucleophilic cysteine of $\mathrm{NCgl} 2478$. The $\mathrm{pKa}$ measurement of the active site cysteines indicates that Cys 21 has an unusual $\mathrm{pKa}$ value lower than 6 and that Cys 24 was the resolving cysteine with a $\mathrm{pKa}$ of 8.09 . Ionized thiol groups (R-SH) extinction coefficient at $240 \mathrm{~nm}$ was utilized to measure pKa values of cysteines of NCg12478 WT $(O)$ and the NCg12478:C24S $(\square)$ and NCg12478:C24S $(\diamond)$. The ratio composed by $240 / 280_{\text {red }}$ and $240 / 280_{\text {ox }}$ in a $\mathrm{pH}$ range of 5 to 10 as fit- ted with the Henderson-Hasselbalch equation. b NCg12478 was not a DsbA-oxidoreductase. The methylene blue RNA intercalating assay was utilized to quantify the activity of RNase I $(0.5 \mu \mathrm{M})$. E. coli RNase I was reduced, and the recovering of activity was monitored in the presence of several enzymes $(5 \mu \mathrm{M}$ NCgl2478 WT or Mrx1). $\mathrm{NCg} 12478$ was unable to catalyze the disulfide bond formation in a previously reduced RNase I. Reactions were performed in duplicate 
Fig. 5 NCg12478 demycothiolated the mixed disulfide between 2-hydroxyethyl disulfide (HED) and MSH (HED-SSM). Activity of proteins were measured with HED-SSM concentration varying in the range $0-20 \mathrm{mM}$ The Michaelis-Menten plots of NCg12478 WT (a), Mrx1 (b), NCg12478:C24S (c), and NCg12478:C21S (d) activity were calculated using the program GraphPad Prism 5.

The data were represented as mean \pm SD of three independent experiments a

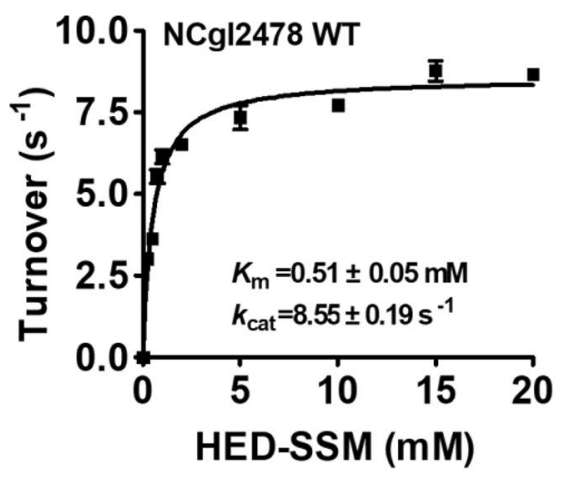

C

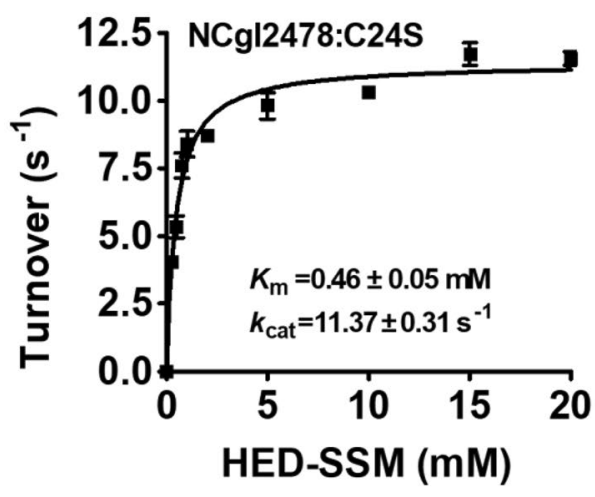

b

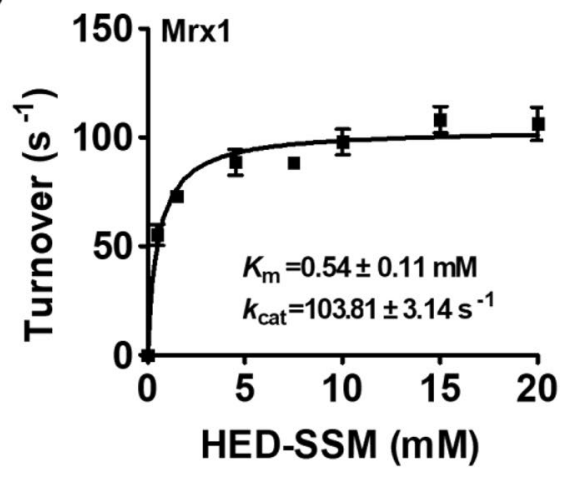

d

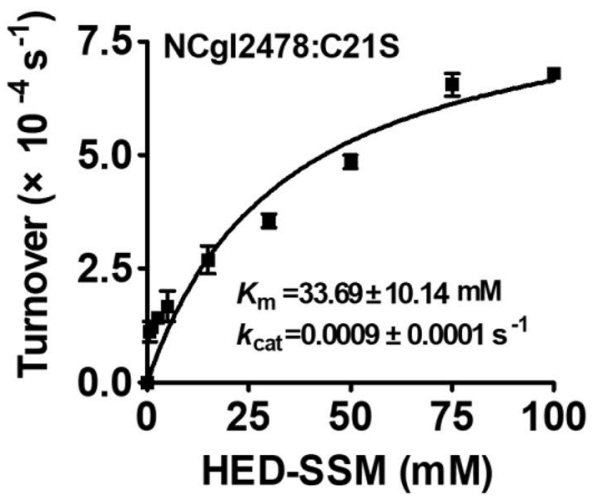

the oxidation of NADPH in the presence of the MSH/Mtr/ NADPH system.

To test the ability of $\mathrm{NCgl} 2478$ to reduce mixed disulfides, we compared its reactivity with C. glutamicum Mrx1 using HED-SSM as substrates (Fig. 5). We followed NADPH consumption coupled to MSH and Mtr at $340 \mathrm{~nm}$. The $K_{\mathrm{m}}$ value, $k_{\text {cat }}$ value, and catalytic coefficient of NCg12478 or Mrx1 for HED-SSM were calculated to be $0.51 \pm 0.05 \mathrm{mM}, 8.55 \pm 0.19 \mathrm{~s}^{-1}$, and $1.68 \pm 0.14 \times 10^{4} \mathrm{M}^{-1} \mathrm{~s}^{-1}$, or $0.54 \pm 0.11 \mathrm{mM}$, $103.81 \pm 3.14 \mathrm{~s}^{-1}$, and $19.22 \pm 0.31 \times 10^{4} \mathrm{M}^{-1} \mathrm{~s}^{-1}$, respectively (Fig. 5a, b). NCg12478:C24S has a slightly higher initial velocity of $11.37 \pm 0.31 \mathrm{~s}^{-1}$ toward HED-SSM, whereas, the NCg12478:C21S was inactive. This cysteine substitution experiment indicated that $\mathrm{NCgl} 2478$ was functioning under a monothiol mode of action where the nucleophilic Cys 21 was required to catalyze mixed disulfide bond reduction. It is worth noting that the activity of Mrx 1 was about 11-fold faster in reducing HED-SSM compared with the $\mathrm{NCgl} 2478$ enzyme when the MSH/Mtr/NADPH pathway was introduced as an electron donor.

\section{NCgl2478 reduced intramolecular disulfide bonds via a dithiol mechanism}

We further checked the ability of NCgl2478 to reduce intramolecular disulfide bonds in an insulin assay (Table 4). When the MSH/Mtr/NADPH pathway was used as an electron donor, the activity of Mrx1 was 2.1-fold faster in reducing insulin compared with $\mathrm{NCgl} 2478$. However, NCg12478 demonstrated no activity upon mutation of the nucleophilic Cys 21 or the resolving Cys24 to serine (Table 4). This led
Table 4 Insulin reduction parameters

\begin{tabular}{|c|c|c|c|c|c|}
\hline \multirow[t]{2}{*}{ Substrates } & \multicolumn{5}{|c|}{ MSH/Mtr/NADPH } \\
\hline & Control $^{\mathrm{a}}$ & $\mathrm{NCgl} 2478$ & NCg12478:C21S & NCg12478:C24S & Mrx1 \\
\hline $\begin{array}{l}\text { Rate of precipitation } \\
\left(A_{600} 10^{-5} \mathrm{~s}^{-1}\right) 2.58 \\
\pm 0.1\end{array}$ & $3.14 \pm 0.3$ & $12.36 \pm 0.05$ & $2.63 \pm 0.2$ & $2.93 \pm 0.2$ & $25.74 \pm 4.1$ \\
\hline Starting point (s) & 2876 & 1598 & 2743 & 2584 & 1215 \\
\hline
\end{tabular}

${ }^{\mathrm{a}}$ Control, reaction without catalyst 
us to conclude that the reduction of insulin occurred via a dithiol mechanism.

\section{SigH positively regulated NCgl2478 expression in C. glutamicum}

Because $C$. glutamicum ncgl2478 mutants exhibited sensitivity in the circumstances of various reagents, qRT-PCR, and lac $Z Y$ activity profiling were employed to examine whether $n c g l 2478$ expression responded to these toxic stress inducers at the transcriptional level. However, no putative promoter was identified upstream of the $n c g l 2478$ gene. Interestingly, further upstream from $n c g l 2478$ was $n c g l 2479$ gene, which is identically orientated as $n c g l 2478$ (Fig. 6a). Thus, we speculated that $n c g l 2478$ was organized in a putative operon with $n c g l 2479$, which were confirmed to be co-transcribed by reverse transcription PCR (Fig. 6b). Based on the basis of the information, a putative-10 region (GAGAAAAAT) and a putative-35 region (TTTCCT) were identified, which localized within the upstream open reading frame of $\mathrm{NCgl} 2479$ (Fig. 6a). According to this phenomenon, we named the promoter DNA fragment of the ncgl2478-ncgl2479 operon as $P_{n c g l 2478 .} \mathrm{NCgl} 2478$ expression was investigated by the lac $Z Y$ activity of $P_{n c g l 2478}:$ :lacZY chromosomal promoter fusion reporter and quantitative real-time RT-PCR (qRTPCR) analysis. As shown in Fig. 6c, the ncgl2478 expression level was significantly increased in the WT(pXMJ19) $\left(P_{n c g l 2478}:: l a c Z Y\right)$ reporter strains treated with various agents, as compared to untreated cells. The result significantly demonstrated that environmental stress induced the expression of $n c g l 2478$ gene and directly conferred resistance of $C$. glutamicum to stress conditions with the enhancement of expression quantity. A similar pattern of $n c g l 2478$ expression in response to different reagents was also observed in qRT-PCR analysis (Fig. 6d).

Because Busche et al. found $\mathrm{NCgl} 2478$ was one of the main targets of the stress-responsive extra-cytoplasmic function-sigma (ECF- $\sigma$ ) factor SigH by microarray analysis, which is strongly linked to the oxidative stress response in C. glutamicum (Busche et al. 2012). Therefore, we tested its regulatory capacity for $\mathrm{NCgl} 2478$. Based on the basis of the information, a putative SigH-binding site was identified, which localized within the upstream open reading frame of $\mathrm{NCgl} 2479$ (Fig. 6a). Moreover, the $n c g l 2479$ promoter DNA element was highly similar to the known recognition site for SigH (Busche et al. 2012). NCg12478 regulation was investigated by chromosomal $P_{n c g l 2478}:$ lacZY fusion reporter and qRT-PCR analysis. As shown in Fig. 6c, $\Delta s i g H$ (strains lacking $s i g H$ gene contained empty pXMJ19) significantly decreased the lacZY activity of the $n c g l 2478$ promoter, almost fully recovered by introducing a plasmid pXMJ19 expressing wild-type $\operatorname{sig} H$ in deletion of $s i g H$ gene in $C$. glutamicum $\left(\Delta \operatorname{sig} H^{+}, \Delta\right.$ sigH was complemented with plasmid pXMJ19 carrying the wild-type $s i g H$ gene). These results demonstrated that C. glutamicum $\mathrm{NCgl} 2478$ was positively regulated by $\mathrm{SigH}$. The positive regulation of $n c g l 2478$ by SigH was also confirmed by qRT-PCR, with the observation that the mRNA levels of $n c g l 2478$ were reduced in the $\Delta s i g H$ mutant and restored to the wild-type level in the complemented strain $\Delta s i g H^{+}$(Fig. 6d). To further determine whether SigH regulated $n c g l 2478$ expression directly, we examined the interaction between SigH and the $n c g l 2478$ promoter using an electrophoretic mobility shift assay (EMSA). Incubation of a 211-bp DNA element containing the $n c g l 2478$ promoter $\left(P_{n c g l 2478}\right)$ sequence $[-993$ to -782 relative to the ATG start codon of the $n c g l 2478$ open reading frame (ORF)] with $\mathrm{His}_{6}$-SigH led to the formation of DNA-protein complexes, and the abundance of such complexes depended on the amount of SigH (Fig. 6e left panel). However, both BSA instead of $\mathrm{His}_{6}-\mathrm{SigH}$ and a 211 bp control DNA fragment amplified from the $n c g l 2478$ ORF region showed no detectable binding (Fig. 6e, lanes 6 and 7). To further verify the predicted SigH binding site, the 211-bp promoter DNA containing the mutagenesis sequence of the predicted SigH-binding site $\left(P_{n c g / 2478 M}\right)$, the start and stop sites of which were the same as those of a 211-bp DNA element containing the $n c g l 2478$ promoter $\left(P_{n c g l 2478 M}\right)$ sequence was synthesized by Shanghai Biotechnology Co., Ltd. and used (Fig. 6a). As shown in Fig. 6e right panel, mutations in the predicted SigH-binding site disrupted the formation of such complexes. Moreover, promoter DNA mutations in the predicted SigH-binding site caused the extremely low transcription activity of $n c g l 2478$ in WT and $\Delta$ sig $H^{+}$strains, similar to that in the $\Delta s i g H$ mutant (Fig. 6f). Thus, SigH directly activated the expression of $n c g l 2478$ by specifically recognizing an operator within the $n c g l 2478$ promoter region.

\section{Conclusion}

In this study, we revealed a novel MSH-dependent oxidoreductase $\mathrm{NCgl} 2478$ by physiological and biochemical analysis. NCg12478 promoted C. glutamicum resistance to oxidative stress. Its physiological roles in resistance to oxidative stresses were corroborated by its induced expression under various stresses, regulated directly by $\mathrm{SigH}$. Despite its high sequence similarity to DsbA, NCgl2478 did not act as an oxidase. $\mathrm{NCg} 12478$ was less specific in receiving electrons, because both the MSH/Mtr/NADPH and the Trx/TrxR/NADPH pathways regenerated oxidized NCg12478. NCg12478 preferentially linked to the MSH/ Mtr/NADPH electron pathway via monothiol mechanism to reduce $S$-mycothiolated mixed disulfides. NCgl2478 had

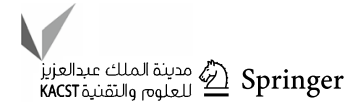


a

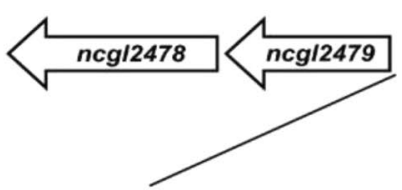

CTTAAGTACCCCTGTTTT GGAGAATGCTCCGAGCCAGGGG

\begin{tabular}{cccc}
\multicolumn{1}{c}{-35} & TCGACTCATG & -10 \\
TACTTTTC TTTCCTCACACACAGTAGCTGCT GAGAAAAAT &
\end{tabular}

$\underset{+1}{\stackrel{\Gamma}{\longrightarrow}}$

GAGGCCTTCATACCGCTCAAGCATCGTACGGGG--. ATG b

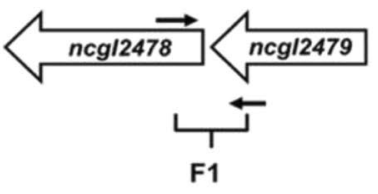

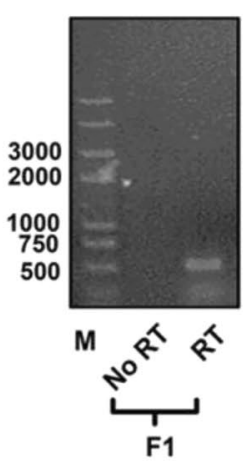

d

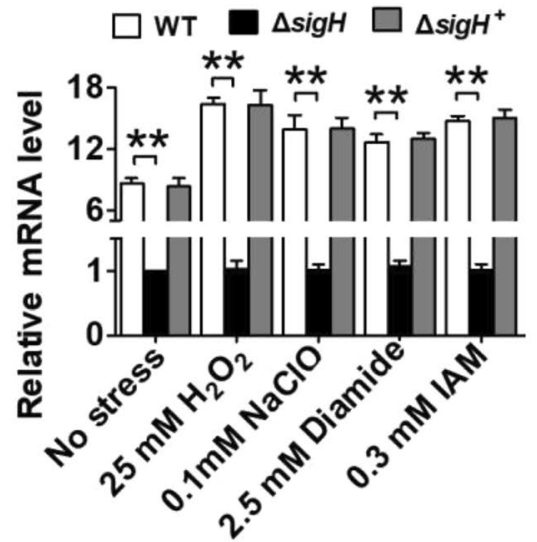

f e
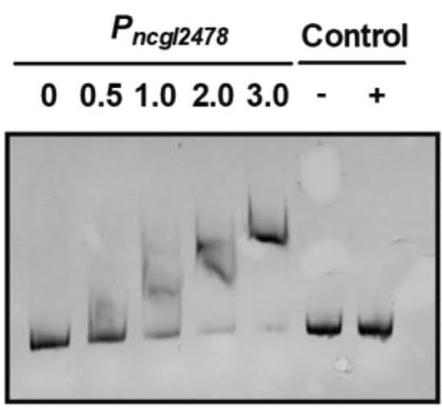

$\begin{array}{llllllll}1 & 2 & 3 & 4 & 5 & 6 & 7 & \text { Lane }\end{array}$
$\mathrm{SigH}(\mu \mathrm{g})$

DNA-Protein

Complexes

Free DNA

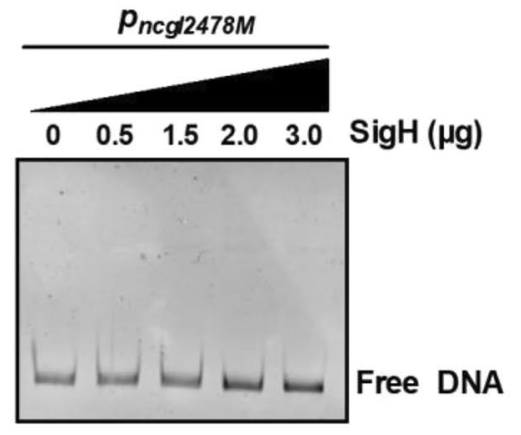

f

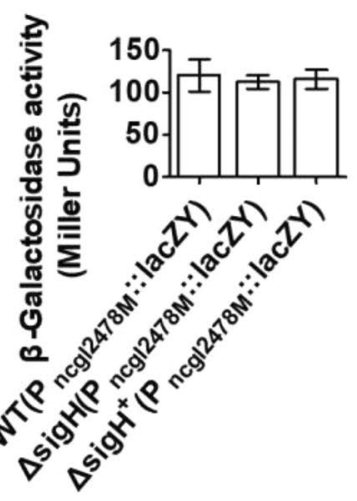

a lower initial velocity toward HED-SSM. Thus, NCg12478 had a similar mode of action, including enzymatic rate, substrate preference, and cell survival under stress, as the previously characterized DsbA-Mrx1 proteins (M. tuberculosis Rv2466c and C. glutamicum NCg12339). Together, our work has uncovered $\mathrm{NCgl} 2478$ as a member of the novel DsbA-Mrx 1 cluster promoted C. glutamicum resistance to oxidative stress.

Acknowledgements This study were supported by the National Natural Science Foundation of China (31970034) and the Research and Innovation Foundation for Graduate Dissertation of Qufu Normal University (LWCXS202130).
Author contributions Meiru Si, Yang Liu and Can Chen designed the research. Yang Liu, Xiaona Li, Jiaxin Luo, Tao Su, and Can Chen performed the research and analyzed the data. Can Chen and Meiru Si supervised the research. Yang Liu and Xiaona Li wrote the paper. Can Chen and Meiru Si revised the paper. All authors read and approved the final manuscript.

Data availability The study investigators have full access to the article datasets.

\section{Declarations}

Conflict of interest The authors declare that they have no conflict of interest.

Ethical approval and consent to participate Not applicable. 
४Fig. 6 Stress response of $n c g l 2478$ in C. glutamicum. a Detailed genetic maps of the regulatory region of NCgl2478. Gray nucleotides indicated the putative binding sites of SigH. The putative transcriptional start site $(+1)$ was shown, and the deduced -35 and -10 promoter regions were boxed. Underlined sequence with bases in bold showed the mutation of SigH binding site. The start codon was underlined in the $n c g l 2478$ upstream region. b Assays for the ncgl2478-ncgl2479 co-transcription by reverse transcription PCR. The operon structure of ncgl2478-ncgl2479 primer where designed for assays and indicated by blank arrows (left panel). Reverse transcription PCR assays for $n c g l 2478-n c g l 2479$ co-transcription (right panel). Negative control PCR reactions omitted the initial reverse transcription step (No-RT). PCR procedure was as follows: reactions were denatured at $95{ }^{\circ} \mathrm{C}$ for $50 \mathrm{~s}$, annealed at $58{ }^{\circ} \mathrm{C}$ for $40 \mathrm{~s}$, extended at $72{ }^{\circ} \mathrm{C}$ for $30 \mathrm{~s}$, and repeated 30 cycles. c $\beta$-Galactosidase analysis of the $n c g l 2478$ promoter activity was performed using the transcriptional $P_{n c g l 2478}:$ lacZY chromosomal fusion reporter expressed in the C. glutamicum RES167 parental strain containing empty pXMJ19 (WT). $100 \mu \mathrm{l}$ of exponentially growing C. glutamicum cells treated with different toxic agents at indicated concentrations for $30 \mathrm{~min}$ was added to the enzyme reaction system. The values represent the mean results from three independent cultivations, with standard errors. $* * P \leq 0.01 ; * P \leq 0.05$. d qRT-PCR assay was performed to analyze the expression of $n c g l 2478$. Exponentially growing $C$. glutamicum cells were exposed to different toxic agents at indicated concentrations for $30 \mathrm{~min}$. The levels of $n c g l 2478$ expression were determined by qRT-PCR. The mRNA levels were presented relative to the value obtained from WT cells without treatment. The values represent the mean results from three independent cultivations, with standard errors. ${ }^{*} P \leq 0.01 ; * P \leq 0.05$. e EMSA was performed to analyze the interactions between $\mathrm{His}_{6}-\mathrm{SigH}$ and the $n c g l 2478$ promoter $\left(P_{n c g l 2478}\right)$ or the promoter mutating the identified SigH binding region $\left(P_{n c g l 2478 M}\right)$. A 211-bp fragment amplified from the $n c g l 2478$ coding region instead of the 211-bp ncgl2478 promoter (lane 7) and BSA instead of SigH (lane 6) in the binding assays were used as negative controls to determine the binding specificity of SigH. f Mutations in the predicted SigH-binding site did not activate the $n c g l 2478$ expression. Relative levels of transcripts were presented as the mean values \pm SD calculated from three sets of independent experiments

\section{Consent for publication Not applicable.}

Open Access This article is licensed under a Creative Commons Attribution 4.0 International License, which permits use, sharing, adaptation, distribution and reproduction in any medium or format, as long as you give appropriate credit to the original author(s) and the source, provide a link to the Creative Commons licence, and indicate if changes were made. The images or other third party material in this article are included in the article's Creative Commons licence, unless indicated otherwise in a credit line to the material. If material is not included in the article's Creative Commons licence and your intended use is not permitted by statutory regulation or exceeds the permitted use, you will need to obtain permission directly from the copyright holder. To view a copy of this licence, visit http://creativecommons.org/licenses/by/4.0/.

\section{References}

Baker LM, Poole LB (2003) Catalytic mechanism of thiol peroxidase from Escherichia coli. Sulfenic acid formation and overoxidation of essential CYS61. J Biol Chem 278(11):9203-9211
Bröer S, Eggeling L, Krämer R (1993) Strains of Corynebacterium glutamicum with different lysine productivities may have different lysine excretion systems. Appl Environ Microbiol 59(1):316-321

Busche T, Silar R, Picmanova M, Patek M, Kalinowski J (2012) Transcriptional regulation of the operon encoding stress-responsive ECF sigma factor SigH and its anti-sigma factor RshA, and control of its regulatory network in Corynebacterium glutamicum. BMC Genomics 13:445

Dalle-Donne I, Milzani A, Gagliano N, Colombo R, Giustarini D, Rossi R (2008) Molecular mechanisms and potential clinical significance of $S$-glutathionylation. Antioxid Redox Signal $10(3): 445-473$

Ellis HR, Poole LB (1997) Novel application of 7-chloro-4-nitrobenzo2-oxa-1,3-diazole to identify cysteine sulfenic acid in the AhpC component of alkyl hydroperoxide reductase. Biochemistry 36(48):15013-15018

Ellman GL (1959) Tissue sulfhydryl groups. Arch Biochem Biophys 82(1):70-77

Gething MJH, Davidson BE (1972) Molar absorption-coefficient of reduced Ellmans reagent: 3-carboxylato-4-nitro-thiophenolate. Eur J Biochem 30:352-353

Greiner-Stoeffele T, Grunow M, Hahn U (1996) A general ribonuclease assay using methylene blue. Anal Biochem 240(1):24-28

Halliwell B, Gutteridge J (1984) Oxygen toxicity, oxygen radicals, transition metals and disease. Biochem J 219(1):1-14

Holmgren A (1979) Glutathione-dependent synthesis of deoxyribonucleotides: purification and characterization of glutaredoxin from Escherichia coli. J Biol Chem 254(9):3664-3671

Jakoby M, Ngouoto-Nkili CE, Burkovski A (1999) Construction and application of new Corynebacterium glutamicum vectors. Biotechnol Tech 13(6):437-441

Jiang GF, Yang J, Li XJ, Cao YJ, Liu XM, Ling J, Wang H, Zhong ZT, Zhu J (2019) Alkyl hydroperoxide reductase is important for oxidative stress resistance and symbiosis in Azorhizobium caulinodans. FEMS Microbiol Lett 366(3):fnz014

Liu YB, Long MX, Yin YJ, Si MR, Zhang L, Lu ZQ, Wang Y, Shen XH (2013) Physiological roles of mycothiol in detoxification and tolerance to multiple poisonous chemicals in Corynebacterium glutamicum. Arch Microbiol 195(6):419-429

Messens J, Collet JF, Van Belle K, Brosens E, Loris R, Wyns L (2007) The oxidase DsbA folds a protein with a nonconsecutive disulfide. J Biol Chem 282(43):31302-31307

Miller JH (1992) A short course in bacterial genetics: a laboratory manual and handbook for Escherichia coli and related bacteria, vol 1. Cold Spring Harbor Laboratory Press, New York

Newton GL, Fahey RC (2008) Regulation of mycothiol metabolism by $\operatorname{sigma}(\mathrm{R})$ and the thiol redox sensor anti- factor RsrA. Mol Microbiol 68(4):805-809

Pedre B, Van Molle I, Villadangos AF, Wahni K, Vertommen D, Turell L, Erdogan H, Mateos LM, Messens J (2015) The Corynebacterium glutamicum mycothiol peroxidase is a reactive oxygen species-scavenging enzyme that shows promiscuity in thiol redox control. Mol Microbiol 96(6):1176-1191

Rawat M, Newton GL, Ko M, Martinez GJ, Fahey RC, Av-Gay Y (2002) Mycothiol-deficient Mycobacterium smegmatis mutants are hypersensitive to alkylating agents, free radicals, and antibiotics. Antimicrob Agents Chemother 46(11):3348-3355

Roos G, Garcia-Pino A, Van Belle K, Brosens E, Wahni K, Vandenbussche G, Wyns L, Loris R, Messens J (2007) The conserved active site proline determines the reducing power of Staphylococcus aureus thioredoxin. J Mol Biol 368(3):800-811

Roos G, Foloppe N, Messens J (2013) Understanding the pK(a) of redox cysteines: the key role of hydrogen bonding. Antioxid Redox Signal 18(1):94-127

Rosado LA, Wahni K, Degiacomi G, Pedre B, Young D, Rubia AG, Boldrin F, Martens E, Marcos-Pascual L, Sancho-Vaello

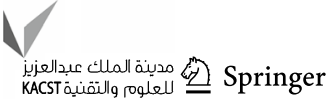


E, Albesa-Jové D, Provvedi R, Martin C, Makarov V, Versées W, Verniest G, Guerin ME, Mateos LM, Manganelli R, Messens J (2017) The antibacterial prodrug activator Rv2466c is a mycothiol-dependent reductase in the oxidative stress response of Mycobacterium tuberculosis. J Biol Chem 292(32):13097-13110

Schäfer A, Tauch A, Jager W, Kalinowshi J, Thierbach G, Pühler A (1994) Small mobilizable multi-purpose cloning vectors derived from the Escherichia coli plasmids pK18 and pK19: selection of defined deletions in the chromosome of Corynebacterium glutamicum. Gene 145(1):69-73

Selles B, Hugo M, Trujillo M, Srivastava V, Wingsle G, Jacquot J, Radi R, Rouhier N (2012) Hydroperoxide and peroxynitrite reductase activity of poplar thioredoxin-dependent glutathione peroxidase 5 : kinetics, catalytic mechanism and oxidative inactivation. Biochem J 442(2):369-380

Sharma SV, Van Laer K, Messens J, Hamilton CJ (2016) Thiol redox and $\mathrm{p} K a$ properties of mycothiol, the predominant low-molecularweight thiol cofactor in the Actinomycetes. ChemBioChem 17(18):1689-1692

Shen XH, Jiang CY, Huang Y, Liu ZP, Liu SJ (2005) Functional identification of novel genes involved in the glutathione-independent gentisate pathway in Corynebacterium glutamicum. Appl Environ Microbiol 71(7):3442-3452

Si M, Long M, Chaudhry MT, Xu Y, Zhang P, Zhang L, Shen X (2014a) Functional characterization of Corynebacterium glutamicum mycothiol S-conjugate amidase. PLoS ONE 9(12):e115075

Si MR, Zhang L, Yang ZF, Xu YX, Liu YB, Jiang CY, Wang Y, Shen $\mathrm{XH}$, Liu SJ (2014b) NrdH redoxin enhances resistance to multiple oxidative stresses by acting as a peroxidase cofactor in Corynebacterium glutamicum. Appl Environ Microbiol 80(5):1750-1762

Si M, Xu Y, Wang T, Long M, Ding W, Chen C, Guan X, Liu Y, Wang Y, Shen X, Liu S (2015a) Functional characterization of a mycothiol peroxidase in Corynebacterium glutamicum that uses both mycoredoxin and thioredoxin system as proton donor for oxidative stress response. Biochem J 469(1):45-57
Si M, Zhang L, Chaudhry MT, Ding W, Xu Y, Chen C, Akbar A, Shen X, Liu SJ (2015b) Corynebacterium glutamicum methionine sulfoxide reductase A uses both mycoredoxin and thioredoxin for regeneration and oxidative stress resistance. Appl Environ Microbiol 81(8):2781-2796

Si M, Chen C, Su T, Che C, Yao S, Liang G, Li G, Yang G (2018a) CosR is an oxidative stress sensing a MarR-type transcriptional repressor in Corynebacterium glutamicum. Biochem $\mathrm{J}$ 475(24):3979-3995

Si M, Su T, Chen C, Liu J, Gong Z, Che C, Li G, Yang G (2018b) OhsR acts as an organic peroxide-sensing transcriptional activator using an S-mycothiolation mechanism in Corynebacterium glutamicum. Microb Cell Fact 17(1):200

Si M, Che C, Li G, Li X, Gong Z, Liu J, Yang G, Chen C (2019) Characterization of $\mathrm{Xi}$-class mycothiol S-transferase from Corynebacterium glutamicum and its protective effects in oxidative stress. Microb Cell Fact 18(1):182

Storz G, Christman MF, Sies H, Ames BN (1987) Spontaneous mutagenesis and oxidative damage to DNA in Salmonella typhimurium. Proc Natl Acad Sci USA 84(24):8917-8921

Su T, Si M, Zhao Y, Liu Y, Yao S, Che C, Chen C (2018) A thioredoxin-dependent peroxiredoxin $\mathrm{Q}$ from Corynebacterium glutamicum plays an important role in defense against oxidative stress. PLoS ONE 13(2):e0192674

Su T, Si M, Zhao Y, Yao S, Che C, Liu Y, Chen C (2019) Function of alkyl hydroperoxidase AhpD in resistance to oxidative stress in Corynebacterium glutamicum. J Gen Appl Microbiol 65(2):72-79

Tauch A, Kirchner O, Löffler B, Götker S, Pühler A, Kalinowski J (2002) Efficient electro transformation of Corynebacterium diphtheriae with a mini-replicon derived from the Corynebacterium glutamicum plasmid pGA1. Curr Microbiol 45(5):362-367

Van Laer K, Buts L, Foloppe N, Vertommen D, Van Belle K, Wahni K, Roos G, Nilsson L, Mateos LM, Rawat M, Nuland NAJ, Messens $\mathbf{J}$ (2012) Mycoredoxin-1 is one of the missing links in the oxidative stress defence mechanism of Mycobacteria. Mol Microbiol 86(4):787-804 